\title{
PROJECTION METHODS FOR INTEGRAL EQUATIONS IN EPIDEMIC
}

\section{HA̧CIA}

Institute of Mathematics Poznan University of Technology

Piotrowo 3A, 60-965 Poznan, Poland

E-mail: 1hacia@math.put.poznan.pl

Received May 22, 2002; revised November 6, 2002

\section{ABSTRACT}

In this paper numerical methods for mixed integral equations are presented. Studied equations arise in the mathematical modeling of the spatio-temporal development of an epidemic. The general theory of these equations is given and used in the projection methods. Projection methods lead to a system of algebraic equations or to a system of Volterra integral equations. The considered theory is illustrated by numerical examples.
\end{abstract}

Key words: Mathematical model of an epidemic, spread of the disease, mixed integral equations, Volterra integral operator, projection method, Galerkin type method.

\section{INTRODUCTION}

Let $M$ be a closed subset of $m$-dimensional Euclidean space $\mathbb{R}^{m}(m=1,2,3)$ representing the habitat of a population susceptible to some contagious disease. Let the functions $S=S(x, t)$ and $I(x, t)$ denote the density of susceptibles and infectives respectively at position $x$ and time $t$. Let $i(x, t, s) d s$ be the density of infectives which were infected some time between $t-s$ and $t-s-d s$. Then

$$
I(x, t)=\int_{0}^{\infty} i(x, t, s) d s
$$

Suppose that the population size is large so that one can consider $S, I$ and $i$ a sufficiently smooth real-valued function of their arguments. The spread of the disease in the given population can be described by a mixed integral 
equation of the form

$u(x, t)=f(x, t)+\int_{0}^{t} \int_{M} S_{0}(y) A(x, t-s, y) g[u(s, y)] d y d s,(x, t) \in D=M \times[0, T]$

Here:

$$
S_{0}(x)=S(0, x)>0, \quad g(y):=1-\exp (-y), \quad f(x, t)=\int_{0}^{t} h(x, s) d s
$$

where

$$
h(x, t)=\int_{0}^{t} \int_{M} i_{0}(s, y) A(x, t+s, y) d y d s, \quad i_{0}(x, s)=i(x, 0, s) .
$$

Assume that:

(i) the disease has permanent immunity, so the transition from $I$ to $S$ does not occur,

(ii) a nonnegative function $A(x, t, y)$ describing the infectivity at position $x$ due to one infective of "age of illness" $t$ at position $y$ determines the infectivity

$$
B(x, t)=\int_{0}^{\infty} \int_{M} i(y, t, s) A(x, s, y) d y d s
$$

Presented model of an epidemic follows from the following system of dynamical equations:

$$
\begin{aligned}
\frac{\partial S}{\partial t}(x, t) & =-S(x, t) B(x, t) \\
i(x, t, 0) & =\frac{\partial S}{\partial t}(x, t) \\
i(x, t, s) & =i(x, t-s, 0)
\end{aligned}
$$

Detailed descriptions and analyses of the above considerations may be found in [2], which leads to a nonlinear integral equation of the mixed type

$$
u(x, t)=f(x, t)+\int_{0}^{t} \int_{M} k(x, t, y, s) g(u(y, s)) d y d s
$$

that in the case $g(u)=u$ is a linear equation. 
In this paper we restrict numerical methods to linear mixed integral equations because the convergence analysis of numerical methods for nonlinear equation depend crucially on the representation of the solution for linear equation.

\section{GENERAL CONSIDERATIONS}

The mixed integral equation

$$
u(x, t)=f(x, t)+\int_{0}^{t} \int_{M} k(x, t, y, s) u(y, s) d y d s,
$$

is considered, where $f$ is given function in domain $D=M \times[0, T](M$ is a compact subset of $m$-dimensional Euclidean space) and $u$ is unknown function in $D$. Given kernel $k$ is defined in domain

$$
\Omega=\{(x, t, y, s): x, y \in M, \quad 0 \leq s \leq t \leq T\} .
$$

Integral equations of this type arise in various physical, mechanical and biological problems (for example - heat conduction theory and diffusion theory).

The general theory for the considered equations in weighted spaces was presented in [4]. Approximate solutions of mixed integral equations were studied in papers [1], [3] - [7]. The mixed integral equation (2.1) can be written in the operator form

$$
u=f+K u
$$

where

$$
(K u)(x, t)=\int_{0}^{t} \int_{M} k(x, t, y, s) u(y, s) d y d s
$$

is the integral operator in that a Volterra part plays the dominant role. On virtue this property we can prove existence and uniqueness of solutions for equation (2.1) in spaces $C$ and $L^{p}(p \geq 1)$.

\section{GALERKIN TYPE METHOD}

Classical Galerkin method for integral equation (2.1) leads to approximate solution of the form

$$
u_{n}(x, t)=\sum_{j=1} c_{j} \chi_{j}(x, t)
$$


where $\left\{\chi_{j}\right\}$ is the orthogonal basis in the space $L^{2}(D)$. Because it is difficult to define such a system we propose the following formula

$$
u_{n}(x, t)=\sum_{i, k=1}^{n} c_{i k} \varphi_{i}(x) \psi_{k}(t)
$$

where $\left\{\varphi_{i}\right\},\left\{\psi_{k}\right\}$ are orthogonal bases in spaces $L^{2}(D)$ and $L^{2}[0, T]$, respectively. Coefficients $\left(c_{i k} i, k=1,2, \ldots, n\right)$ are determined by the orthogonality condition in $L^{2}(D)$ of the form

$$
\left(\varepsilon_{n}, \varphi_{i} \psi_{k}\right)=0, \quad(i, k=1,2, \ldots, n), \quad \text { where } \quad \varepsilon_{n}=u_{n}-f-K u_{n},
$$

is a deviation function. In practice, we restrict our considerations to the orthonormal basis. Then we get the following system of linear algebraic equations

$$
c_{i k}=f_{i k}+\sum_{j, m=1}^{n} c_{j m} k_{j m, i k}, \quad i, k=1,2, \ldots, n
$$

where

$$
\begin{aligned}
& f_{i k}=\int_{0}^{T} \int_{M} f(x, t) \varphi_{i}(x) \psi_{k}(t) d x d t, \\
& k_{j m, j k}=\int_{0}^{T} \int_{M}\left[\int_{0}^{t} \int_{M} k(x, t, y, s) \varphi_{j}(y) \psi_{m}(s) d y d s\right] \varphi_{i}(x) \psi_{k}(t) d x d t .
\end{aligned}
$$

Theorem 3.1. Let $\left\{\varphi_{i}\right\},\left\{\psi_{k}\right\}$ be orthonormal complete systems in the spaces $L^{2}(M)$ and $L^{2}[0, T]$, respectively. If $f \in L^{2}(D)$ and $k \in L^{2}(\Omega)$, then system (3.2) is uniquely solvable and the sequence defined by formula (3.1) converges to unique solution of equation (2.1) in the space $L^{2}(D)$.

The proof is similar as in the case of the Fredholm integral equation and it is based on the Fourier series theory.

We illustrate the presented method for the following integral equation

$$
u(x, t)=f(x, t)+\int_{0}^{t} \int_{-1}^{1} k(x, t, y, s) u(y, s) d y d s, \quad t \in[0,1]
$$

using in (3.1) as a basis the orthonormal Legendre'a polynomials. 


\section{Implementation in Maple V}

$$
\begin{aligned}
& A:=p \rightarrow \int_{-1}^{1} \varphi(p, x)^{2} d x \\
& B:=q \rightarrow \int_{0}^{1} \psi(q, t)^{2} d t \\
& q_{n}:=(p, q) \rightarrow \int_{0}^{1} \int_{-1}^{1} f(x, t) \varphi(p, x) \psi(q, t) d x d t \\
& V q_{n}:=\operatorname{vector}(n \times n) \\
& \text { for } p 1 . . n \\
& \text { for } q 1 . . n \\
& V q_{n}[n(p-1)+q]:=-q_{n}(p, q) \\
& \text { end } \\
& \text { end } \\
& o p\left(V q_{n}\right) \\
& k_{n}:=(i, j, p, q) \rightarrow \\
& \int_{0}^{1} \int_{-1}^{1}\left[\int_{0}^{1} \int_{-1}^{1} k(x, t, y, s) \varphi(i, y) \psi(j, s)\right] d y d s \cdot \varphi(p, x) \psi(q, t) d x d t \\
& M k_{n}:=\operatorname{matrix}(n \times n, n \times n) \\
& \text { for } p 1 . . n \\
& \text { for } q 1 . . n \\
& \text { row }:=n(p-1)+q \\
& \text { for } i 1 \text {..n } \\
& \text { for } j 1 . . n \\
& M k_{n}[\text { row, } n(i-1)+j]:=k_{n}(i, j, p, q) \text { end end } \\
& M k_{n}[\text { row, row }]:=M k_{n}[\text { row, row }]-A(p) B(q) \text { end end } \\
& \text { for } i \text { to } n \\
& \text { for } j \text { to } n \\
& c_{i j}:=\operatorname{solve}[n(i-1)+j] \text { od od } \\
& \text { op }\left(M k_{n}\right) \\
& \text { solve }:=\text { linsolve }(M k n, V q n) \\
& o p(c) \\
& u d:=(x, t) \rightarrow \sum_{j=1}^{n}\left(\sum_{i=1}^{n} c_{i j} \varphi(i, x)\right) \psi(j, t) .
\end{aligned}
$$


I. Numerical examples

Example 1

$u(x, t)=x \sin t+\frac{1}{3} x^{2} t^{2} e^{t} \cos t-\frac{1}{3} x^{2} t^{2} e^{t} \sin t-\frac{1}{3} x^{2} t^{2}+\int_{0}^{t} \int_{-1}^{1} y x^{2} t^{2} e^{s} u(y, s) d y d s$

Absolute errors:
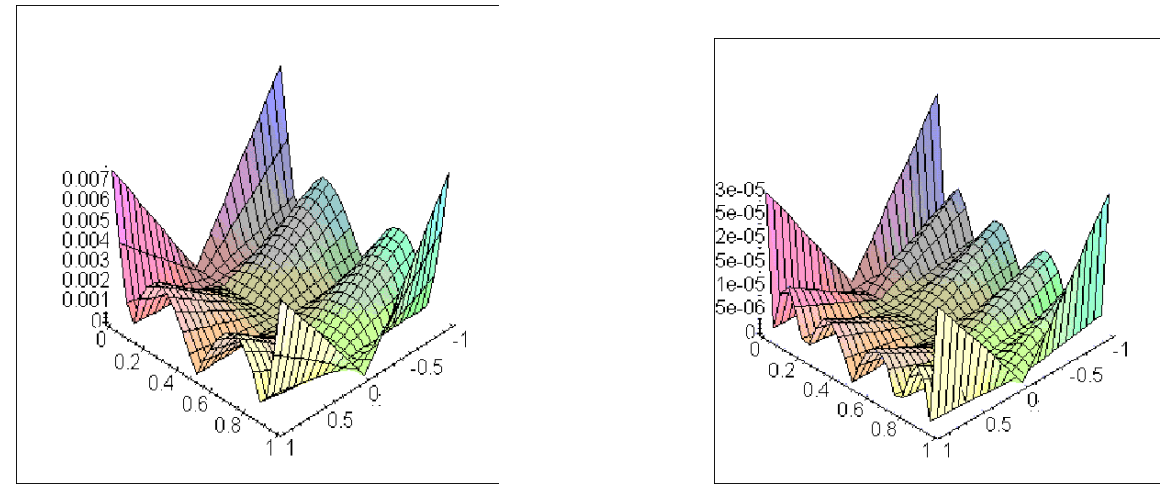

Figure 1. $n=3$

$n=5$

\section{Example 2}

$$
u(x, t)=x+\sin t-\frac{2}{3} e^{t}+\frac{2}{3}+\int_{0}^{t} \int_{-1}^{1} y e^{s} u(y, s) d y d s
$$

Absolute errors:

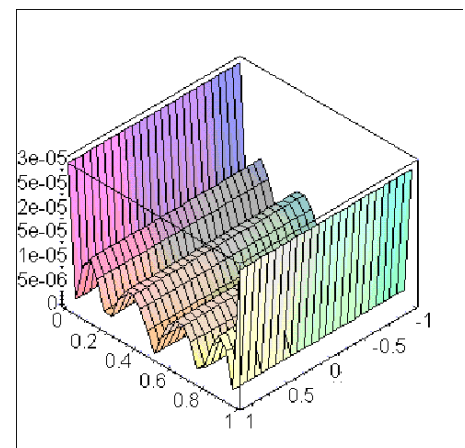

Relative errors:

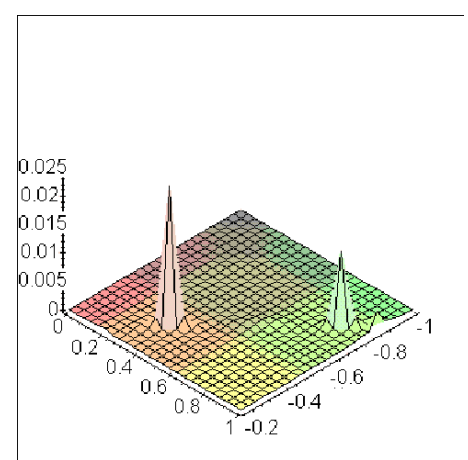

Figure 2. $n=5$ 

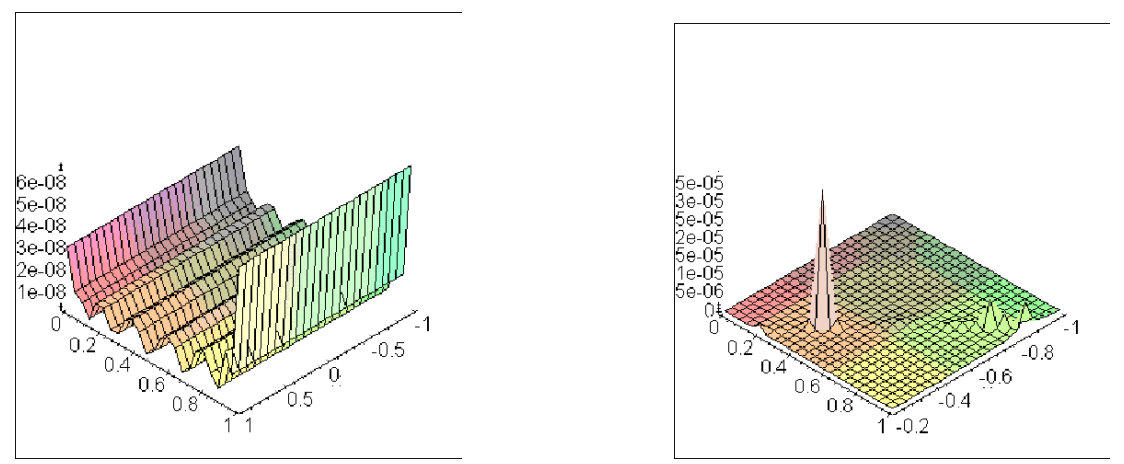

Figure 3. $n=10$

\section{Example 3}

$$
u(x, t)=e^{-t} x^{2}-\frac{2}{3} t^{3} x^{2}+\int_{0}^{t} \int_{-1}^{1} x^{2} t^{2} e^{s} u(y, s) d y d s
$$

Absolute errors:

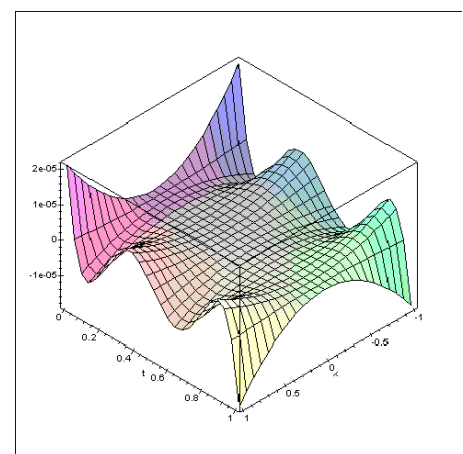

Figure 4. $n=5$

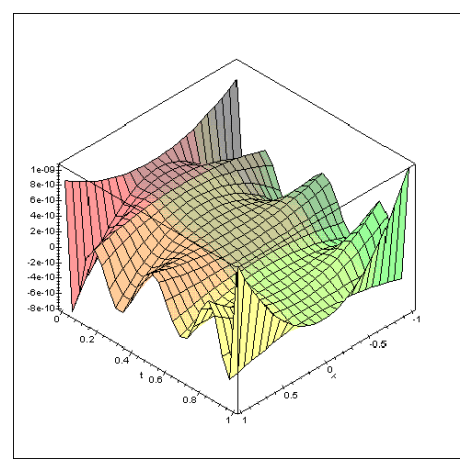

$n=8$

The relative errors for $n=6 \mathrm{i}$ are given in the Table 1. Dependence of average relative error of a number of basic functions is shown in Table 2. a).

Example 4 In the case of the equation

$$
u(x, t)=e^{x} t^{2}-\frac{2}{3} t^{3} x^{2}+\int_{0}^{t} \int_{-1}^{1} e^{-y} x^{2} u(y, s) d y d s
$$

we get the following relative errors which are presented in Table 2,b). 
Table 1.

\begin{tabular}{cccc}
\hline$t \backslash x$ & $\pm 0,2$ & $\pm 0,6$ & $\pm 1,0$ \\
\hline 0,0 & $.9685 \mathrm{e}-6$ & $.9625 \mathrm{e}-6$ & $.9619 \mathrm{e}-6$ \\
0,2 & $.2146 \mathrm{e}-6$ & $.2093 \mathrm{e}-6$ & $.2089 \mathrm{e}-6$ \\
0,4 & $.1208 \mathrm{e}-6$ & $.1247 \mathrm{e}-6$ & $.1250 \mathrm{e}-6$ \\
0,6 & $.1266 \mathrm{e}-6$ & $.1270 \mathrm{e}-6$ & $.1273 \mathrm{e}-6$ \\
0,8 & $.3432 \mathrm{e}-6$ & $.3480 \mathrm{e}-6$ & $.3487 \mathrm{e}-6$ \\
1 & $.2300 \mathrm{e}-5$ & $.2315 \mathrm{e}-5$ & $.2317 \mathrm{e}-5$ \\
\hline
\end{tabular}

Table 2.

a)

\begin{tabular}{cc}
\hline$n$ & Relative errors \\
\hline 4 & $.337 \mathrm{e}-3$ \\
5 & $.163 \mathrm{e}-4$ \\
6 & $.665 \mathrm{e}-6$ \\
7 & $.328 \mathrm{e}-7$ \\
\hline
\end{tabular}

b)

\begin{tabular}{cc}
\hline$n$ & Relative errors \\
\hline 4 & $.506 \mathrm{e}-2$ \\
5 & $.549 \mathrm{e}-3$ \\
6 & $.615 \mathrm{e}-5$ \\
7 & $.344 \mathrm{e}-8$ \\
\hline
\end{tabular}

Remark 3.1. For $n>11$ algorithm is weakly stable and the absolute errors are increasing with $n$. This conclusion follows from the quadrature formula and a number of the system of algebraic equations.

\section{PROJECTION METHOD}

Consider the following integral equation

$$
u_{n}(x, t)=f_{n}(x, t)+\int_{0}^{t} \int_{M} k_{n}(x, t ; y, s) u_{n}(y, s) d y d s
$$

where

$$
f_{n}(x, t)=\sum_{i, k=1}^{n} f_{i k} \chi_{i k}(x, t), \quad k_{n}(x, t, y, s)=\sum_{i, k=1}^{n} \sum_{j=1}^{n} k_{i k, j l} \chi_{i k}(x, t) \chi_{j l}(y, s)
$$

and

$$
\chi_{i k}(x, t)=\varphi_{i}(x) \psi_{k}(t)
$$


where $\left\{\varphi_{i}\right\},\left\{\psi_{k}\right\}$ - orthonormal basis in the spaces $L^{2}(M)$ and $L^{2}[0, T]$, respectively,

$$
\begin{aligned}
f_{i k} & =\left(f, \chi_{i k}\right)=\int_{0}^{T} \int_{M} f(x, t) \chi_{i k}(x, t) d x d t \\
k_{i k, j l} & =\left(k, \chi_{l k, j l}\right)=\int_{0}^{T} \int_{M}\left[\int_{0}^{t} \int_{M} k(x, t ; y, s) \chi_{j l}(y, s) d y d s\right] \chi_{i k}(x, t) d x d t .
\end{aligned}
$$

Putting this expressions in (4.1) we get

$$
u_{n}(x, t)=\sum_{i, k=1}^{n}\left(f_{i k}+\sum_{j, l=1}^{n} k_{i k j l} \int_{0}^{t} \int_{M} \chi_{j l}(y, s) u_{n}(y, s) d y d s\right) \chi_{i k}(x, t) .
$$

Introducing the notation

$$
c_{i k}(t)=f_{i k}+\sum_{j, l=1}^{n} k_{i k j l} \int_{0}^{t} \int_{M} \chi_{j l}(y, s) u_{n}(y, s) d y d s,
$$

we get the approximate solution of equation (4.1) in the form

$$
u_{n}(x, t)=\sum_{i, k=1}^{n} c_{i k} \chi_{i k}(x, t)
$$

Putting (4.6) into (4.5) we obtain the following system of linear Volterra integral equations

$$
c_{i k}(t)=f_{i k}+\sum_{j, l=1}^{n} k_{i k j l} \int_{0}^{t} \int_{M} \chi_{j l}(y, s)\left[\sum_{p, q=1}^{n} c_{p q}(s) \chi_{p q}(y, s)\right] d y d s,
$$

for calculating the functions $c_{i k}(i, k=1,2, \ldots, n)$. Putting (4.2) into (4.7) we have

$$
c_{i k}(t)=f_{i k}+\sum_{i j=1}^{n} k_{i k j l} \sum_{p, q=1}^{n} \int_{0}^{t} \int_{M} c_{p q}(s) \varphi_{j}(y) \psi_{l}(s) \varphi_{p}(y) \psi_{q}(s) d y d s .
$$

On virtue the orthonormality of the system $\left(\varphi_{p}\right)$ in $L^{2}(M)$, i.e.

$$
\int_{M} \varphi_{p}^{2}(y) d y=1, \quad \int_{M} \varphi_{j}(y) \varphi_{p}(y)=0, \quad j \neq p,
$$


we get the special system of linear Volterra integral equations

$$
c_{i k}(t)=f_{i k}+\sum_{l, p, q=1}^{n} k_{i k p l} \int_{0}^{t} c_{p q}(s) \psi_{l}(y) \psi_{q}(s) d s \quad(i, k=1,2, \ldots, n)
$$

Theorem 4.1. Let $\left\{\varphi_{i}\right\}$ be orthonormal complete system in $L^{2}(M)$ and $\left\{\psi_{i}\right\}$ be orthogonal complete system in $L^{2}[0 . T]$. If $f \in L^{2}(D)$ and $k \in L^{2}(\Omega)$, then system (4.8) is uniquely solvable in the space $L^{2}[0 . T]$ and the sequence defined by formula (4.6) converges to unique solution of equation (2.1) in the space $L^{2}(D)$.

Proof. We rewrite integral equation (4.1) rewrite in the operator form

$$
u_{n}=f_{n}+K_{n} u_{n}
$$

where $K_{n}$ is the Volterra-Fredholm operator of form (2.3) determined by the kernel $k_{n}$. Then we get

$$
u_{n}-u=f_{n}-f+\left(K_{n}-K\right) u_{n}+K\left(u_{n}-u\right)
$$

From paper [4] we obtain

$$
u_{n}-u=(I-K)^{-1}\left[\left(f_{n}-f\right)+\left(K_{n}-K\right) u_{n}\right]
$$

and

$$
\left\|u_{n}-u\right\|_{2} \leq\left\|(I-K)^{-1}\right\|\left\lfloor\left\|\left(f_{n}-f\right)\right\|_{2}+\left\|k_{n}-k\right\|_{2}\left\|u_{n}\right\|_{2}\right\rfloor .
$$

The convergence follows from Fourier series theory because

$$
\begin{gathered}
\left\|f_{n}-f\right\|_{2} \underset{n \rightarrow \infty}{\longrightarrow} 0 \\
\left\|k_{n}-k\right\|_{2} \underset{n \rightarrow \infty}{\longrightarrow} 0
\end{gathered}
$$

\section{GALERKIN-FOURIER METHOD}

In this section we propose the following algorithm for equation (2.1)

$$
u_{n}(x, t)=\sum_{j=1}^{n} a_{j}(t) \varphi_{j}(x)
$$


for $(x, t) \in D, D=M \times[0, T]$, where $\left\{\varphi_{j}\right\}$ is an orthonormal and complete system in $L^{2}(M) ;\left\{a_{j}\right\}$ is a solution for a system of Volterra integral equations

$$
a_{j}(t)=f_{j}(t)+\sum_{k=1}^{n} \int_{0}^{t} k_{j k}(t, s) a_{k}(s) d s, \quad j=1,2, \ldots, n,
$$

here

$$
\begin{aligned}
& f_{j}(t)=\int_{M} f(x, t) \varphi_{j}(x) d x, \quad j=1,2, \ldots, n \\
& k_{j k}(t, s)=\int_{M} \int_{M} k(x, t, y, s) \varphi_{j}(x) \varphi_{k}(y) d y d x, \quad k, j=1,2, \ldots, n .
\end{aligned}
$$

Lemma 5.1. If $f \in L^{2}(D)$ and $k \in L^{2}(\Omega)$, then function defined by (5.1) is a unique solution of equation

$$
u_{n}(x, t)=f_{n}(x, t)+\int_{0}^{t} \int_{M} k_{n}(x, t, y, s) u_{n}(y, s) d y d s,
$$

in the space, $L^{2}(D)$, where

$$
f_{n}(x, t)=\sum_{k=1}^{n} f_{k}(t) \varphi_{k}(x), \quad k_{n}(x, t, y, s)=\sum_{j=1}^{n} \sum_{k=1}^{n} k_{j k}(t, s) \varphi_{j}(x) \varphi_{k}(y) .
$$

Proof. Putting (5.4) in (5.3) we get

$$
u_{n}(x, t)=\sum_{k=1}^{n} u_{k}(t) \varphi_{k}(x)
$$

where

$$
u_{k}(t)=f_{k}(t)+\sum_{j=1}^{n} \int_{0}^{t} \int_{M} k_{j k}(t, s) \varphi_{j}(x) u_{n}(y, s) d y d s, \quad k=1,2, \ldots, n .
$$

Next, due to orthonormality of the system $\left\{\varphi_{k}\right\}$ we get the following system of linear Volterra integral equations

$$
u_{k}(t)=f_{k}(t)+\sum_{j=1}^{n} \int_{0}^{t} k_{j k}(t, s) u_{j}(s) d s, k=1,2, \ldots, n,
$$


which has a unique solution $\left\{u_{j}\right\}, j=1,2, \ldots, n$ in $L^{2}[0, T]$ such that $u_{j}(t)=$ $a_{j}(t)$ for every $j=1,2, \ldots, n$.

Theorem 5.1. If $f \in L^{2}(D)$ and $k \in L^{2}(\Omega)$, then a sequence $\left\{u_{n}\right\}$ defined by formula (5.1) is convergent in $L^{2}(D)$ to a unique solution of equation (2.1) and an error estimate

$$
\left\|u_{n}-u\right\|_{2} \leq \frac{c}{1-c \delta_{n}}\left[\left\|f-f_{n}\right\|_{2}+\|u\|_{2} \delta_{n}\right]
$$

holds, here

$$
c=\left\|(I-K)^{-1}\right\|, \quad \delta_{n}=\left\|k_{n}-k\right\|_{2} .
$$

Proof is similar as in Theorem 4.1.

\section{CONCLUSIONS}

The mathematical model of an epidemic was reduced to integral equation of the mixed type. In this paper we proposed iterative and projection methods for solving linear integral equations. Presented methods lead to a system of linear algebraic equations or a system of Volterra integral equations.

\section{REFERENCES}

[1] H. Brunner. On the numerical solution of nonlinear Volterra-Fredholm integral equations. SIAM J. Numer. Anal., 27, 987 - 1000, 1990.

[2] O. Diekmann. Thresholds and traveling for the geographical spread of infection. J. Math Biology, 6, 109 - 130, 1978.

[3] L. Hacia. On approximate solutions for integral equations of the mixed type. Zeit.Ang.Math.Mech., 76, 415 - 416, 1996.

[4] L. Ha̧cia. On integral equations in space-time. Demon. Math., 32, 795 - 805, 1999.

[5] J.P. Kauthen. Continuous time-collocation methods for Volterra-Fredholm integral equations. Numer.Math., 56, 409 - 429, 1989.

[6] M.I. Tivončuk. On one variant of the method of averaging functional corrections for solution linear integral equations of the mixed type. Diff. Uravn., 2(9), $1228-1238$, 1966. (in Russian)

[7] I.N. Tukalevska. On one approximate method for solving linear integral equations of the mixed type in the space $L^{P}$. Naukova Dumka, Kiev, 1966. (in Ukrainian)

\section{Projekciniai metodai integralinėms lygtims epidemiologijoje}

L. Hạcia

Pateikiami skaitiniai metodai mišrioms integralinèms lygtims. Nagrinejjamos lygtys modeliuoja epidemijų dinamiką erdvejje ir laike. Apżvelgta tokių lygčių bendroji teorija, ji panaudota projekciniuose metoduose. Projekciniai metodai leidżia suvesti użdavini i algebriniu lygčiu sistemą arba i Volteros integralines lygtis. Nagrinejjami metodai iliustruojami skaitiniais pavyzdżiais. 